Article

\title{
Potential Cultivation of Lactobacillus pentosus from Human Breastmilk with Rapid Monitoring through the Spectrophotometer Method
}

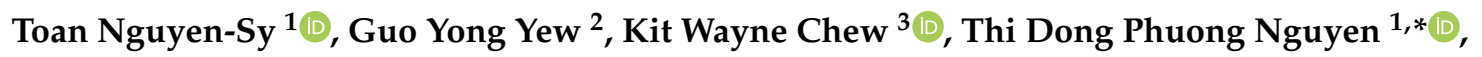 \\ Thi Ngoc Thu Tran ${ }^{1}$, Thi Dieu Huong Le ${ }^{1}$, Chau Tuan Vo ${ }^{4}$, Hoang Kim Pham Tran ${ }^{5}$, \\ Muhammad Mubashir ${ }^{6, *}$ and Pau Loke Show ${ }^{2, *(D)}$ \\ 1 Department of Chemical Engineering and Environment, University of Technology and Education-The \\ University of Danang, 48 Cao Thang St., Danang 550000, Vietnam; thutoantamly@gmail.com (T.N.-S.); \\ ttnthu@ute.udn.vn (T.N.T.T.); ltdhuong@ute.udn.vn (T.D.H.L.) \\ 2 Department of Chemical and Environmental Engineering, Faculty of Science and Engineering, University of \\ Nottingham Malaysia, Jalan Broga, Semenyih 43500, Selangor Darul Ehsan, Malaysia; \\ keby5ygy@nottingham.edu.my \\ 3 School of Energy and Chemical Engineering, Xiamen University Malaysia, Sepang 43900, Selangor Darul \\ Ehsan, Malaysia; kitwayne.chew@xmu.edu.my \\ 4 Department of Biology and Environmental Science, The Danang University of Science and Education, \\ 459 Ton Duc Thang St., Danang 550000, Vietnam; vctuan@ued.udn.vn \\ 5 Le Quy Don High School for the Gifted Danang, Danang 550000, Vietnam; kim76nk2003@gmail.com \\ 6 Department of Chemical Engineering and Chemistry, Eindhoven University of Technology, \\ 5600 MB Eindhoven, The Netherlands \\ * Correspondence: ntdphuong@ute.udn.vn (T.D.P.N.); m.mubashir@tue.nl (M.M.); \\ pauloke.show@nottingham.edu.my (P.L.S.)
}

Received: 8 June 2020; Accepted: 15 July 2020; Published: 29 July 2020

check for updates

\begin{abstract}
The present study focused on the development of a new method to determine the lag phase of Lactobacillus in breast milk which was attained during the 1st, 3rd, and 6th month (M1, M3, and M6). The colonies' phylogenetic analysis, derived from the 16S rRNA gene sequences, was evaluated with genus Lactobacillus pentosus and achieved a similarity value of 99\%. Raman spectroscopy in optical densities of $600 \mathrm{~nm}$ (OD600) were used for six consecutive days to observe the changes of the cell growth rate. The values of OD600 were well fitted with the regression model. From this work, M1 was found to be the longest lag phase in $18 \mathrm{~h}$, and it was $17 \%$ to $27 \%$ longer compared to M3 and M6, respectively. However, the samples of M3 and M6 showed the shortest duration in reaching 0.5 of OD600 $\mathrm{nm}(16 \mathrm{~h})$ which was enhanced by $80 \%$ and $96 \%$ compared to M1, respectively. These studies will be of significance when applied in determining the bacteria growth curve and in assessing the growth behavior for the strain in human breast milk.
\end{abstract}

Keywords: Lactobacillus isolation; lag phase; bacteria sequencing; breast milk

\section{Introduction}

Bacterial growth can be presented in four phases: lag phase, exponential phase, stationary phase, and death phase. The comprehension of lag phase plays an important role in many aspects of the biotechnological field. As known, once bacteria are transferred to a new medium, the metabolite energy will be depleted in the cells and cause termination of the cell growth [1,2]. This phenomenon is explained by the differences between original media and the new culture. On the other hand, there is a lag phase where bacteria might adapt to the new media's conditions. During this phase, organisms increase officially in size but have no change in number. 
The determination of the microbial growth through the optical density (OD) is an effective and conventional parameter to be observed from the growth phases of microbials. According to Ren et al. [3], the work adapted Raman spectroscopy of OD600 to enable the continuous analysis of the growth phases which is found to be marker-free, and subsequently the technique obtained different metabolic states from the strain cells through spectra during the different phases. In general, OD600 is specified to determine the relationship between the colony forming unit (CFU) and growing phases. Modelling the bacterial growth curve has been reported by several research works [4-7]. The growth curve enables other incubation production derived by microorganisms to observe the cell concentrations and make comparison $[8,9]$. The prediction of the cell growth rate can be applied on the growth model in which it can be derived from the beginning of the transferring time $[1,7,8]$. Meanwhile, the lag phase can be ignored from the transferring time and by obtaining a regression model to trace the lag phase. These studies will be applied in determining the bacteria growth curve and to determine the growth behavior for the strain in human breast milk.

Breast milk has been known to contain a significant amount of beneficial microorganism for cell culture $[10,11]$. Besides, parents with no prior drug prescriptions during pregnancy, the mother's breastmilk will contain serotonin which is the natural compound for assisting newborns to sleep [12,13]. While the concurrent microbiota from breastmilk contains probiotic that may have a positive influence on the immunity and digestive system depending on the number of Ig-secreting cells [14]. The drugs which may affect the newborns are mostly by the psychoactive drugs, such as antidepressants, lithium, carbamazepine, and valproate, which further decrease the beneficial strains that emerge from breastmilk [15]. Lactobacillus strains are one of the most beneficial bacteria which are highly considered as antimicrobial and probiotic potential organisms [10,11,16-18]. Breast milk contains strains of beneficial bacteria, such as Lactobacillus, to sustain a high-quality digestive system for the newborn [19-21].

For determining bacterial growing phases, a small volume of microorganism will be cultured in a selective medium, and their OD600 will be observed over the time. The determination of lag phases of microbes is therefore difficult to determine with the high accuracy of time. The observation from the growing phases of a microbial in a medium need to be done for several days, while to observe the changes in OD600 through Raman spectrophotometer will be performed in a few hours. The need to understand the growth kinetics of Lactobacillus strain in human breastmilk isolates from Man, Rogosa, and Sharpe (MRS) medium is primarily useful for cultivation of lactobacilli and for the study on the influence of time and prediction on the cell growth concentration. Moreover, the data may be used to simulate mathematical models for problems involving the rate of growth and relationship of the specific growth rate with the substrate during the strains' growth period [22]. The bacteria cell growth kinetics are an autocatalytic reaction according to each cell metabolite cycle. Growth kinetics would directly influence the dry cell weight, optical density, cell on plate per counts, at the same time, indirectly influencing the nutrient content such as protein, adenosine triphosphate (ATP) and deoxyribonucleic acids (DNA) molecules [23]. In the culture growth, there are several uncertainties that exist in the growth kinetic data as the microorganism will adapt to the changing environmental. The growth kinetics model may resolve the analytical difficulty when the experiment is not in the conventional growth pattern and allow for comparison with the developed mathematical model toward the experiment data. Therefore, the bacteria growth species in the same medium (breastmilk) would have a control data based on the mathematical equation from this experiment.

In this study, the lag phases from the microorganism was determined through the mathematical regression model which was able to verify the accuracy deviation. Besides, lag phase is related to the time when the bacteria have not started to divide, and this period is known as the preparation stage for bacteria to harvest nutrients while adapting to the new environmental condition [24]. Therefore, this research was conducted with two main objectives: (i) to propose a simple method for determining the lag phase and (ii) to compare the growth phases of bacteria from breastmilk to develop the proposed method. 


\section{Materials and Methods}

\subsection{Lactobacillus Isolation}

Breast milk from the 1st, 3rd, and 6th month (hereby denoted as M1, M3, and M6) were collected each to fill 3 bottles of $125 \mathrm{~mL}$ of milk samples (not during the postpartum period) from selected healthy female patients from Danang Hospital, Vietnam. Prior to inoculating the microorganism in MRS selective broth (Merck, HoChiMinh City, Vietnam) as an enrichment media, these samples of $15 \mathrm{~mL}$ were centrifuged at $5000 \times g$ for 5 min to withdraw $1 \mathrm{~mL}$ of supernatant into $15 \mathrm{~mL}$ of MRS broth. This broth with microbial was incubated for $24 \mathrm{~h}$ at $37^{\circ} \mathrm{C}$. After incubation, $100 \mu \mathrm{L}$ of enriched microbial was spread on MRS agar with $0.5 \%$ of calcium carbonate by a glass spreader, and incubated again at $37{ }^{\circ} \mathrm{C}$ under anaerobic condition for $48 \mathrm{~h}$. The 30 milky white colonies in total from M1, M3, and M6 sprouted on an agar plate were chosen to characterize their biochemical properties such as Gram staining, catalase, oxidase test, mobility, and indole production. The colonies, which were isolated and distinguished as Lactobacillus bacteria, were kept in glycerol 20\% (Merck, Vietnam) as a stock culture at $-20^{\circ} \mathrm{C}$ for further phylogenetic analysis. All samples' data presented were performed in triplicate.

\subsection{Biochemical Screening, PCR Reaction}

The Gram staining, catalase, oxidase test, motility, and indole test was performed as a beginning of Lactobacillus screening. The colonies consisted of Gram-positive, catalase-negative, oxidase test-negative, and indole-negative were selected for DNA extraction. The microorganism enriched overnight in sub-cultured media at $30^{\circ} \mathrm{C}$ after it was extracted by Kit AquaPure Genomic Isolation (Bio Rad, Hercules, CA, USA). Foremost, centrifugation at 13,000 rpm for $10 \mathrm{~min}$ was performed on the enriched cells for collecting the pellet and further treated by $300 \mu \mathrm{L}$ of Genomic DNA Lysis Solution. Then $1.5 \mu \mathrm{L}$ of RNase was added in this suspension to be homogenized by vortex, and then the homogenous suspension was incubated at $37^{\circ} \mathrm{C}$ for $5 \mathrm{~min}$. The solution was further adjusted using $100 \mu \mathrm{L}$ of Protein Precipitation Buffer and vortexed for $20 \mathrm{~s}$ for incubated suspension. The solution obtained was centrifuged at 13,000 rpm for $5 \mathrm{~min}$ to harvest the supernatant and transferred to a new tube. Three hundred microliters of isopropanol (2-propanol) was added to this tube to precipitate the DNA which was harvested by centrifugation at 13,000 rpm for $15 \mathrm{~min}$. The DNA precipitation was rinsed by $1 \mathrm{~mL}$ of $70 \%$ ethanol, then was centrifuged 13,000 rpm for $5 \mathrm{~min}$. The DNA precipitation was dried at room temperature and was adjusted to $50 \mu \mathrm{L}$ of DNA hydration solution. The DNA extraction product was examined by gel electrophoresis on $0.8 w / v$ of agarose gel (Bio Rad, America) and was stored at $-40{ }^{\circ} \mathrm{C}$ for further PCR reaction.

For PCR reaction, the $16 \mathrm{~S}$ rRNA gene segment amplification reaction for sequencing using primers 27F (5'-AGAGTTTGATCCTGGCTCAG-3') and 1492R (5'-GGTTACCTTGTTACGACTT-3) was performed. The PCR component consisted of $6 \mu \mathrm{L}$ of master mix, $10 \mu \mathrm{mol}$ of per primer, $50 \mathrm{ng}$ of genomic DNA, and $12 \mu \mathrm{L}$ of distilled water. After being denatured for $95 \mathrm{~min}$ and treated with the PCR thermal cycle for $95^{\circ} \mathrm{C}$ for $1 \mathrm{~min}$, subsequently, at a temperature of $55^{\circ} \mathrm{C}$ for $1 \mathrm{~min}$, and, lastly, at $72{ }^{\circ} \mathrm{C}$ for $1.5 \mathrm{~min}$, this sequence was repeated for 30 cycles. The PCR reaction was then incubated at $72{ }^{\circ} \mathrm{C}$ for $10 \mathrm{~min}$. Finally, PCR products were tested by electrophoresis with $0.8 \% w / v$ of agarose gel and were sequenced by the First BASE Laboratories Sdn Bhd, Malaysia. As a result, sequencing identification were checked with the GeneBank to manipulate the advanced BLAST which was available at the US National Library of Medicine [25].

\subsection{The Regression Model Analysis}

One colony of M1, M3, and M6 chosen from the sub-culture, which well indicated the Lactobacillus sequencing, was dropped in an Erlenmeyer flask containing $100 \mathrm{~mL}$ of MRS broth. A single cell was inoculated from a Petri dish into $5 \mathrm{~mL}$ of the MRS broth in test tube and incubated at $37 \pm 2{ }^{\circ} \mathrm{C}$ for the observation on the cell growth. The cells reached $\sim 0.3$ and was determined using UV-Vis 
spectrophotometer (Shimadzu 1800) at OD600 for a period of 7 days. The Raman spectrometry was performed through cell aliquots in triplicate according to Ren et al. [3].

The software Sigmaplot Verion 14 was used to determine the regression equation. The growth of Lactobacillus was presented as the exponential growth curve. Generally, the growth equation was described as follows:

$$
F=a[1-\exp (-b t)]
$$

where $a$-the potential growth in OD600; $b$-constant; $t$-time in hour.

Most microorganisms require a duration to adapt to the new conditions and environmental surroundings. The lag phase is represented by the time shown in Equation (1). The growth curve was modified to Equation (2) as follows:

$$
F=y_{0}+a[1-\exp (-b t)]
$$

where $y_{0}$-OD600, $a$-growth in OD600; $b$-constant; $t$ - time in hour.

\subsection{Lag Phase Determination}

Since the lag phase duration consumed hours to days of duration, depending on the growing conditions or different microbial strains, the exponential growth phase of microbials was supposed to start at a time point out of zero. The lag phase duration would be presented as Equation (3) below:

$$
t_{\text {lag }}=-b^{-1} \ln \sqrt{\frac{y_{0}+a}{a}}
$$

where $y_{0}, a$, and $b$ are similar as in Equations (1) and (2).

\subsection{Determination of 0.5 OD600}

Microbial growth after the lag phase are varying; hence, the growing time to reach 0.5 OD600 was determined after the lag phase. Equation (4) is described as follows:

$$
t_{0.5 \mathrm{OD}}=-b^{-1} \ln \frac{y_{0}+a-0.5}{a}
$$

where $y_{0}, a$, and $b$ are similar as in Equations (1) and (2).

\section{Result and Discussion}

\subsection{Lactobacillus Identification}

The 30 colonies isolated from M1, M3, and M6 resulted in the biochemical tests to identify its strains, such as lactobacilli, and displayed a similarity of more than $99 \%$ to a type of Lactobacillus pentosus and $99.51 \%$ to a type of Lactobacillus plantarium (Table 1). The samples collected from different time points was for studying how time affects the lag phase activity such as metabolic and cell size. The bacteria population growth may affect the reduction in nutrient content in the breastmilk. All bacterial 16S rDNA gene sequences were entrusted in GenBank using the accession numbers MT026914, MT026915, MT026916, and MT026917. This bacteria strain is a class of Bacilli belonging to the family of Lactobacillaceae which is commonly found in human body intestines. This strain assists to break down lactose molecules from milk. The chemical composition from the breast milk supported the Lactobacillus sp. growth and enzyme activity which could be further transferred and used to produce daily goods such as yogurt drinks [26,27]. Apart from obtaining this strain of bacteria in the fermentation of milk goods, cereal- and soy-based foods in a reported experiment have shown that breastmilk associated with glucose and lipids have the ability to culture healthy and beneficial bacteria strains [28]. Lactic acids are commonly found for in production of yogurt drink in the form of 
Lactobacillus sp. strain which could survive in high acidity environments such as gastric and intestinal juices [29].

Table 1. The phylotypes of colonies isolated from1st month (M1), 3rd month (M3), and 6th month (M6) breast milk.

\begin{tabular}{ccccc}
\hline Colonies Isolated & $\begin{array}{c}\text { Number of } \\
\text { Identical }\end{array}$ & $\begin{array}{c}\text { Sequence Length, } \\
\text { Similarity }\end{array}$ & Most Similar Type Strain & $\begin{array}{c}\text { Accession } \\
\text { Number }\end{array}$ \\
\hline M1 & 8 & $1231,99.51 \%$ & Lactobacillus plantatirum & MT026917 \\
M3 & 12 & $1000,99.9 \%$ & Lactobacillus plantatirum & MT026916 \\
M6 & 10 & $1233,99 \%$ & Lactobacillus pentosus & MT026915 \\
\hline
\end{tabular}

\subsection{Lactobacilli Growth Curve}

The growth curves of M1, M3, and M6 modeled by the regression model as described in Equation (2) is shown in Table 2. All results were well fitted to the model with a high correlation $\left(R^{2}>\right.$ 0.92). It is clear to see that M1 had the highest growth rate, equivalent to 2.08 , followed by M3. This result showed that the Lactobacillus growth rate with the highest rate was in the first stage of the mother's milk during month 1 and slowed down in the 3rd and 6th months. However, the potential OD600 of M1 and M3 were in high similarity with 1.348 and 1.329, respectively. The value was slightly higher than M6 which was 0.948. The potential value in the optical density also showed a declining trend. According to the literature, this current experiment is the first to report a growth rate of $L$. pentosus in breast milk decreasing over time, creating an impact on the relevant field of studies.

Table 2. Regression model for growth of L. pentosus (exponential rise to maximum, single, 3 parameter), run by Sigmaplot Version 14. The equation described is Equation (2) where $y_{0}, a$, and $b$ are constants and $t$ is the cultured time.

\begin{tabular}{cccccc}
\hline & $y_{\mathbf{0}}$ & $\boldsymbol{a}$ & $\boldsymbol{b}$ & $\boldsymbol{R}^{\mathbf{2}}$ & Potential Absorbance at OD600 \\
\hline M1 & -0.732 & 2.08 & 0.26 & 0.984 & 1.348 \\
M3 & -0.26 & 1.588 & 0.1015 & 0.926 & 1.329 \\
M6 & -0.328 & 1.276 & 0.021 & 0.971 & 0.984 \\
\hline
\end{tabular}

\subsection{Lag Phase Determination}

By obtaining the model for determination of the lag phases of M1, M3, and M6, which is seen in Table 3, M1 was shown as having the longest time for the lag phase with $16.8 \mathrm{~h}$; this is longer than M3 and M6 by 4.6 and $2.9 \mathrm{~h}$, respectively. In contrast, to reach 0.5 OD600 after lag phases, M1 had the shortest duration of time which was $18 \mathrm{~h}$, while the others were 51-55\% higher compared to M1 for M3 and M6 (Table 3).

Table 3. The duration for growth phases of L. pentosus from breast milk determined by regression model (hours).

\begin{tabular}{cccc}
\hline (Colonies) & Lag Phase & Reaching 0.5 OD600 & Reaching 0.5 OD600 after Lag Phase \\
\hline M1 & $16.8 \pm 0.21$ & $34.8 \pm 0.18$ & $18.0 \pm 1.81$ \\
M3 & $12.2 \pm 0.34$ & $44.6 \pm 0.65$ & $32.3 \pm 0.38$ \\
M6 & $13.9 \pm 0.10$ & $49.1 \pm 1.27$ & $35.2 \pm 0.97$ \\
\hline
\end{tabular}

Indeed, the model could be referenced to understand the ability to adapt a new environment for other bacteria. It is noted that M1 had the longest lag phase compared to the rest. This result mentioned that the bacteria in the early stages of a mother's milk takes a longer duration to be activated, but then shortens the period overtime. The reaching of 0.5 OD600 was supposed to see the potential of the early growth of bacteria, which is also an important factor for culturing most strains of the bacteria. 
In this research, M1 had the shortest time to reach 0.5 OD600, confirming that Lactobacillus in the early stage of mother's milk provided the highest growth ability. The Lactobacillus in M1 reached 0.5 OD600 as the fastest among the three samples but was also considered as the highest potential in OD600. This suggests that M1 had an optimum condition which enhanced the Lactobacillus growth rate. The mechanism of Lactobacillus in breast milk made it less active over time.

\subsection{Applied of Regression Model in Determining Lag Phase of Lactobacillus}

Equation (1), as shown in Figure 1, has been applied in many models regarding growth curves and other fields which increases gradually compared to the potential of growth by observing OD600 [4-8]. However, these models could not deplete the lag phase. This study has concluded that the bacteria noticeably consumed several hours for the lag phase that ranged from 12.2-16.8 $\mathrm{h}$. By fitting the regression model, the onset of the exponential phase time was determined as described by the lag phase in Equation (3). Therefore, the mathematical model value was supported by the practical experiment value. It is noteworthy that the lag phase requires a period of more than half a day before going into the exponential phase ( $\log$ phase). The equation developed can be fitted into a general concept for biological growth and alternative phenomenological approach for other studies based on similar experimental practices to assist in those studies.

(a)

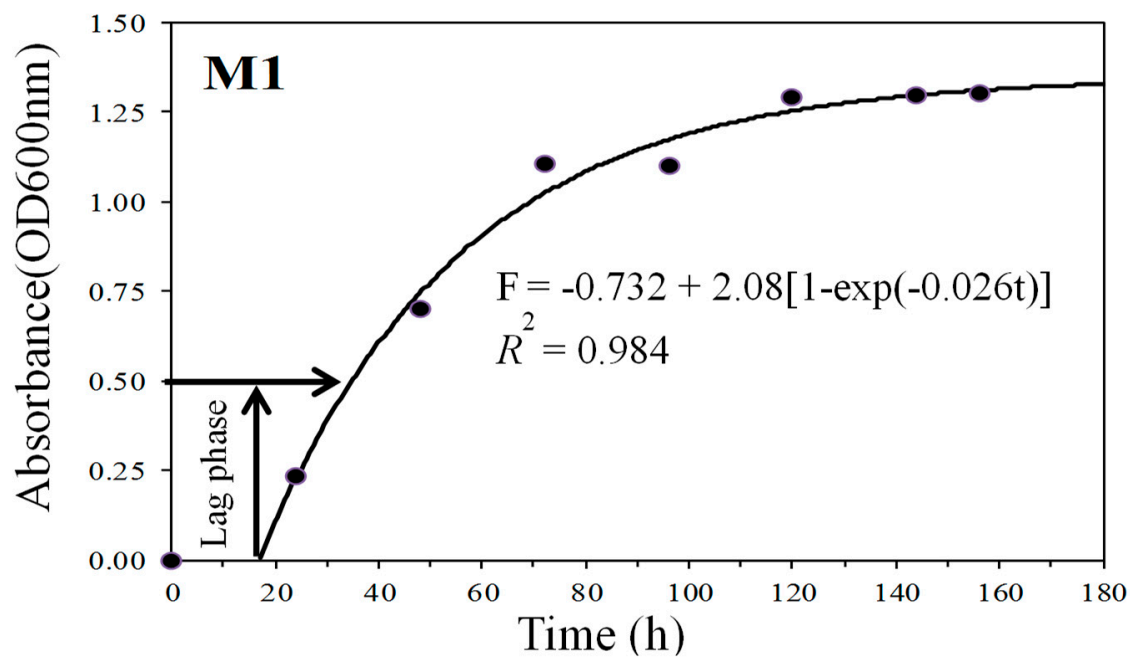

(b)

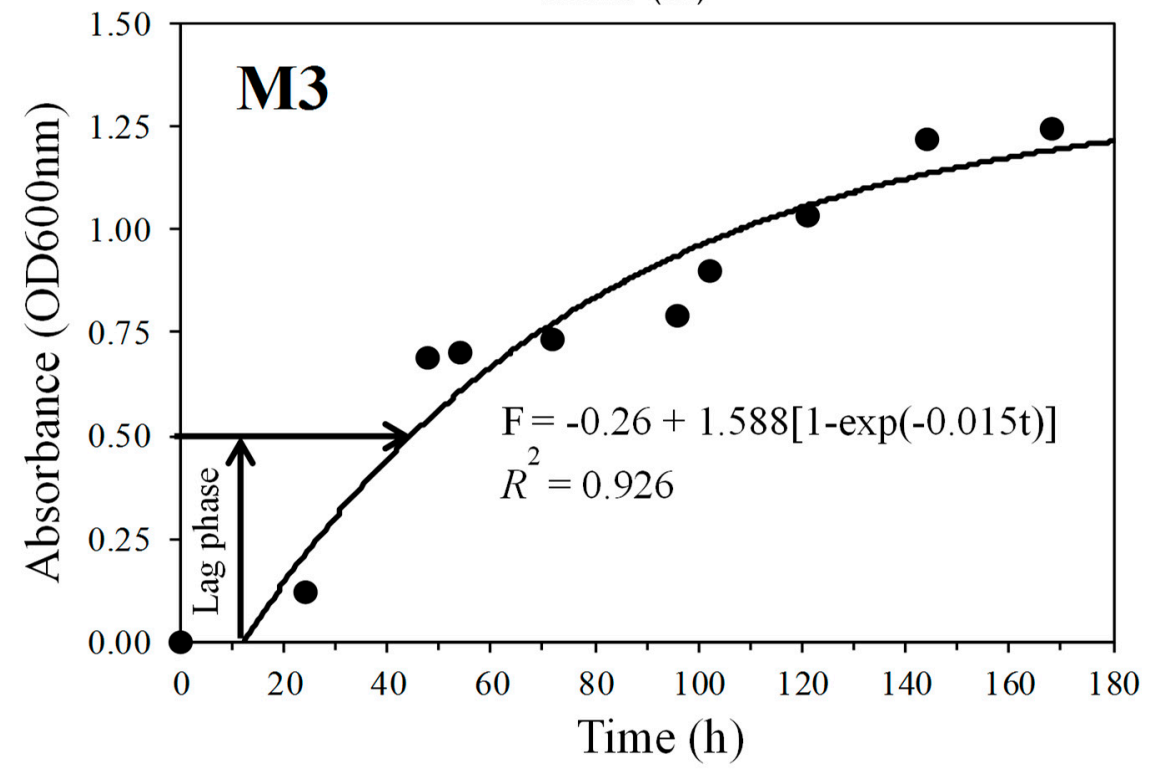

Figure 1. Cont. 
(c)

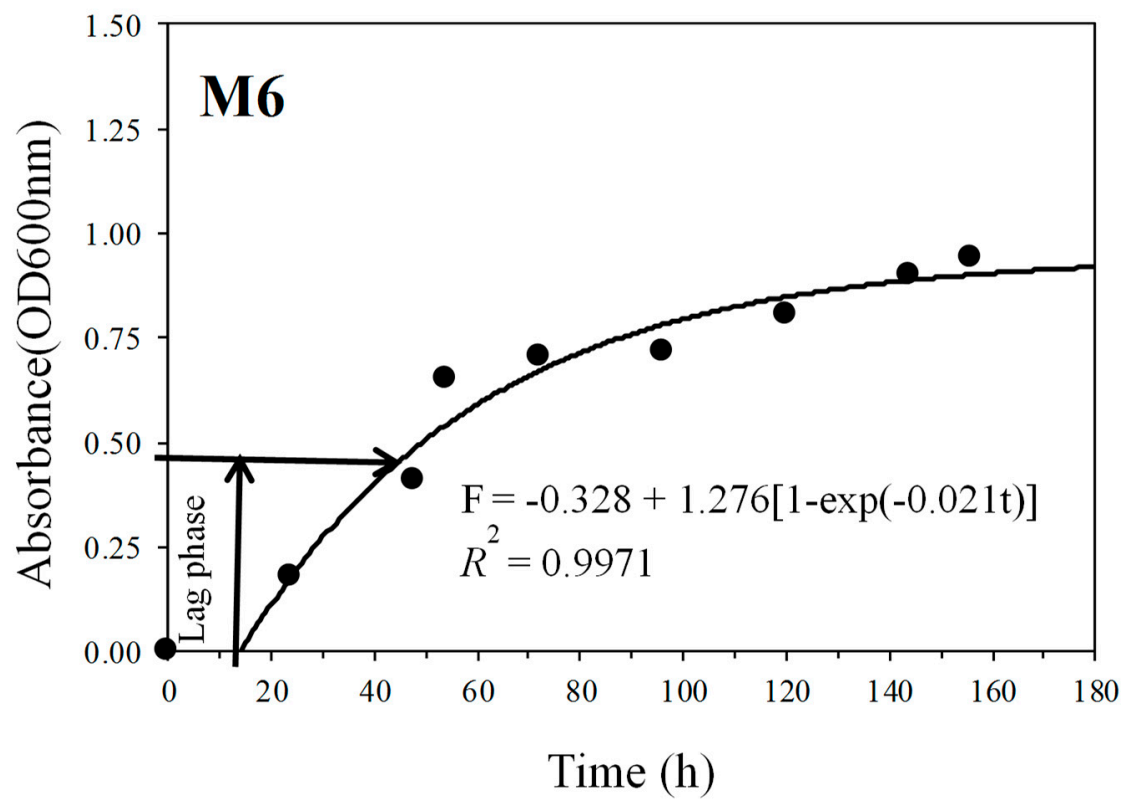

Figure 1. The growth curve of the 1st (a), 3rd (b), and 6th (c) month of breast milk fitted to the regression model in Equation (2). The black points were observed OD600, and the continuous curve line was modelled by Sigmaplot Version 14 .

\section{Conclusions}

The growth rate of Lactobacillus in breast milk was suited well according to the regression model with high correlation $\left(R^{2}>0.92\right)$. It is proposed that the model could be applied to estimate the lag phase as well as early growth phases of bacteria. In addition, Lactobacillus pentosus isolated from the first month of the breast milk has the most potential as a medium for growth. The early stages of the exponential phase were found to decrease in trend after the third month of the breast milk which may conclude the nutrient degradation from the breast milk. Future research could be performed on different strains of bacteria using later or intermediate stages of breast milk while applying other mathematical orders and equations to predict the growth pattern.

Author Contributions: Conceptualization, T.D.P.N. and P.L.S.; methodology, T.N.-S. and G.Y.Y.; software, T.N.T.T. and T.D.H.L.; validation, G.Y.Y. and K.W.C.; formal analysis, M.M.; investigation, C.T.V. and H.K.P.T.; data curation, T.N.-S. and T.D.P.N.; writing - original draft preparation, T.N.-S.; writing-review and editing, G.Y.Y. and K.W.C.; supervision, T.D.P.N., M.M. and P.L.S.; project administration, K.W.C. and P.L.S.; funding acquisition, T.D.P.N. and P.L.S. All authors have read and agreed to the published version of the manuscript.

Funding: This research was funded by the Vietnam Vingroup Innovation Foundation under grant number VINIF.2019.TS.63. The genome sequencing was provided and validated by First BASE Laboratories Sdn Bhd, Malaysia. This work was supported by the Fundamental Research Grant Scheme, Malaysia [FRGS/1/2019/STG05/UNIM/02/2] and MyPAIR-PHC-Hibiscus Grant [MyPAIR/1/2020/STG05/UNIM/1].

Conflicts of Interest: The authors declare no financial or commercial conflict of interest.

\section{References}

1. Yew, G.Y.; Tham, T.C.; Show, P.-L.; Ho, Y.-C.; Ong, S.K.; Law, C.L.; Song, C.; Chang, J.-S. Unlocking the Secret of Bio-additive Components in Rubber Compounding in Processing Quality Nitrile Glove. Appl. Biochem. Biotechnol. 2020, 191, 1-28. [CrossRef] [PubMed]

2. Yeang, C.-H. Integration of Metabolic Reactions and Gene Regulation. Mol. Biotechnol. 2011, 47, 70-82. [CrossRef] [PubMed]

3. Ren, Y.; Ji, Y.; Teng, L.; Zhang, H. Using Raman spectroscopy and chemometrics to identify the growth phase of Lactobacillus casei Zhang during batch culture at the single-cell level. Microb. Cell Factories 2017, 16, 233. [CrossRef] [PubMed]

4. Baranyi, J. Stochastic modelling of bacterial lag phase. Int. J. Food Microbiol. 2002, 73, 203-206. [CrossRef] 
5. Baranyi, J.; Roberts, T.A. A dynamic approach to predicting bacterial growth in food. Int. J. Food Microbiol. 1994, 23, 277-294. [CrossRef]

6. Zwietering, M.; De Koos, J.; Hasenack, B.; De Witt, J.; Van't Riet, K. Modeling of bacterial growth as a function of temperature. Appl. Environ. Microbiol. 1991, 57, 1094-1101. [CrossRef]

7. Zwietering, M.; Jongenburger, I.; Rombouts, F.; Van't Riet, K. Modeling of the bacterial growth curve. Appl. Environ. Microbiol. 1990, 56, 1875-1881. [CrossRef]

8. Cheng, W.; Padre, A.T.; Sato, C.; Shiono, H.; Hattori, S.; Kajihara, A.; Aoyama, M.; Tawaraya, K.; Kumagai, K. Changes in the soil $\mathrm{C}$ and $\mathrm{N}$ contents, $\mathrm{C}$ decomposition and $\mathrm{N}$ mineralization potentials in a rice paddy after long-term application of inorganic fertilizers and organic matter. Soil Sci. Plant Nutr. 2016, 62, 212-219. [CrossRef]

9. García, C.; Rendueles, M.; Díaz, M. Microbial amensalism in Lactobacillus casei and Pseudomonas taetrolens mixed culture. Bioprocess Biosyst. Eng. 2017, 40, 1111-1122. [CrossRef]

10. Martín, R.; Jiménez, E.; Olivares, M.; Marín, M.; Fernández, L.; Xaus, J.; Rodríguez, J. Lactobacillus salivarius CECT 5713, a potential probiotic strain isolated from infant feces and breast milk of a mother-child pair. Int. J. Food Microbiol. 2006, 112, 35-43. [CrossRef]

11. Martín, R.; Olivares, M.; Marín, M.L.; Fernández, L.; Xaus, J.; Rodríguez, J.M. Probiotic potential of 3 lactobacilli strains isolated from breast milk. J. Hum. Lact. 2005, 21, 8-17. [CrossRef]

12. Vitale, S.G.; Laganà, A.S.; Muscatello, M.R.A.; La Rosa, V.L.; Currò, V.; Pandolfo, G.; Zoccali, R.A.; Bruno, A. Psychopharmacotherapy in pregnancy and breastfeeding. Obstet. Gynecol. Surv. 2016, 71, 721-733. [CrossRef] [PubMed]

13. Lagana, A.S.; Triolo, O.; D’Amico, V.; Cartella, S.M.; Sofo, V.; Salmeri, F.M.; Bokal, E.V.; Spina, E. Management of women with epilepsy: From preconception to post-partum. Arch. Gynecol. Obstet. 2016, 293, 493-503. [CrossRef]

14. Rinne, M.; Kalliomaki, M.; Arvilommi, H.; Salminen, S.; Isolauri, E. Effect of probiotics and breastfeeding on the bifidobacterium and lactobacillus/enterococcus microbiota and humoral immune responses. J. Pediatr. 2005, 147, 186-191. [CrossRef]

15. Ram, D.; Gowdappa, B.; Ashoka, H.; Eiman, N. Psychopharmacoteratophobia: Excessive fear of malformation associated with prescribing psychotropic drugs during pregnancy: An Indian perspective. Indian J. Pharmacol. 2015, 47, 484. [CrossRef]

16. Anandharaj, M.; Sivasankari, B. Isolation of potential probiotic Lactobacillus oris HMI68 from mother's milk with cholesterol-reducing property. J. Biosci. Bioeng. 2014, 118, 153-159. [CrossRef]

17. Huang, H.; Song, X.; Yang, S. Development of a RecE/T-Assisted CRISPR-Cas9 Toolbox for Lactobacillus. Biotechnol. J. 2019, 14, 1800690. [CrossRef]

18. Li, F.; Zhou, H.; Zhou, X.; Yi, R.; Mu, J.; Zhao, X.; Liu, W. Lactobacillus plantarum CQPC05 Isolated from Pickled Vegetables Inhibits Constipation in Mice. Appl. Sci. 2019, 9, 159. [CrossRef]

19. Todorov, S.D.; Dicks, L.M.T. Parameters affecting the adsorption of plantaricin 423 , a bacteriocin produced by Lactobacillus plantarum 423 isolated from sorghum beer. Biotechnol. J. 2006, 1, 405-409. [CrossRef]

20. Splechtna, B.; Nguyen, T.-H.; Zehetner, R.; Lettner, H.P.; Lorenz, W.; Haltrich, D. Process development for the production of prebiotic galacto-oligosaccharides from lactose using $\beta$-galactosidase from Lactobacillus sp. Biotechnol. J. 2007, 2, 480-485. [CrossRef]

21. Tajabadi, N.; Ebrahimpour, A.; Baradaran, A.; Rahim, R.A.; Mahyudin, N.A.; Manap, M.Y.A.; Bakar, F.A.; Saari, N. Optimization of $\gamma$-aminobutyric acid production by Lactobacillus plantarum Taj-Apis362 from honeybees. Molecules 2015, 20, 6654-6669. [CrossRef] [PubMed]

22. Nor, Z.O.; El-Enshasy, H.A.; Roslinda, A.M.; Sarmidi, M.R.; Ramlan, A.A. Kinetics of cell growth and functional characterization of probiotic strains Lactobacillus delbrueckii and Lactobacillus paracasei isolated from breast milk. Dtsc. Lebensm.-Rundsch. 2009, 105, 444-450.

23. Sakthiselvan, P.; Meenambiga, S.S.; Madhumathi, R. Kinetic Studies on Cell Growth. In Cell Growth; IntechOpen: London, UK, 2019.

24. Bertrand, R.L. Lag phase is a dynamic, organized, adaptive, and evolvable period that prepares bacteria for cell division. J. Bacteriol. 2019, 201, 1-21. [CrossRef]

25. NCBI. Basic Local Alignment Search Tool (BLAST); National Library of Medicine: Bethesda, MA, USA, 2020. 
26. Delgado, S.; Guadamuro, L.; Flórez, A.B.; Vázquez, L.; Mayo, B. Fermentation of commercial soy beverages with lactobacilli and bifidobacteria strains featuring high $\beta$-glucosidase activity. Innov. Food Sci. Emerg. Technol. 2019, 51, 148-155. [CrossRef]

27. Jha, A.K.; Prasad, K. Biosynthesis of metal and oxide nanoparticles using Lactobacilli from yoghurt and probiotic spore tablets. Biotechnol. J 2010, 5, 285-291. [CrossRef] [PubMed]

28. Lee, E.; Jung, S.-R.; Lee, S.-Y.; Lee, N.-K.; Paik, H.-D.; Lim, S.-I. Lactobacillus plantarum strain $\ln 4$ attenuates diet-induced obesity, insulin resistance, and changes in hepatic mrna levels associated with glucose and lipid metabolism. Nutrients 2018, 10, 643. [CrossRef] [PubMed]

29. Nishinari, K.; Fang, Y.; Nagano, T.; Guo, S.; Wang, R. 6-Soy as a food ingredient. In Proteins in Food Processing, 2nd ed.; Yada, R.Y., Ed.; Woodhead Publishing: Philadelphia, PA, USA, 2018; pp. 149-186. [CrossRef]

(C) 2020 by the authors. Licensee MDPI, Basel, Switzerland. This article is an open access article distributed under the terms and conditions of the Creative Commons Attribution (CC BY) license (http://creativecommons.org/licenses/by/4.0/). 